\title{
DATACENTRE TOTAL COST OF OWNERShip (TCO) MODELS: A SURVEY
}

\author{
Doaa Bliedy, Sherif Mazen and Ehab Ezzat \\ Department of Information System, Cairo University, Cairo
}

\begin{abstract}
Datacenter total cost of ownerships (TCO) tools and spreadsheets can be used to estimate the capital and operational costs required for running datacenters. These tools are helpful for business owners to improve and evaluate the costs and the underlying efficiency of such facilities or evaluate the costs of alternatives, such as off-site computing. Well understanding of the cost drivers of TCO models can provide more opportunities to business owners to control costs. In addition, they also introduce an analytical structure in which anecdotal information can be cross-checked for consistency with other well-known parameters driving data center costs. This work focuses on comparing between number of proposed tools and spreadsheets which are publicly available to calculate datacenter total cost of ownership (TCO) ,The comparison is based on many aspects such as what are the parameters included and not included in such tools and whether the tools are documented or not. Such an approach presents a solid ground for designing more and better tools and spreadsheets in the future.
\end{abstract}

\section{KEYWORDS}

Datacenters, TCO model, TCO parameters, IT software license cost, network, server

\section{INTRODUCTION}

Data centers can be defined as any space whose main function is to house servers [1] or computing devices that are in-use, i.e., are powered on and performing functions. Although a small computing room inside a multipurpose building can be believed as a data center, the term is traditionally used to define buildings whose major function is to locate these servers. In this conventional sense, human occupancy is limited to small Information Technology (IT) support groups who may have office space within the building - these office spaces are small relative to the total size of the building. These facilities differ greatly from most buildings from a construction perspective. For example, mechanical and electrical systems account for $70 \%$ of construction costs in data centers, in contrast to only $15 \%$ of costs in commercial buildings [2].

Nowadays, network-based activities or internet are the major reasons for using datacenters. Datacenters locate servers so that they can Manipulate large amount of data, talk to each other or to other computer networks and process user interactions with server-based software tools or web portals.

The other main purpose of the existence of data centers today is the need for managing the critical data and operations such as organization's databases and email sending As a result, reliabilityi.e., its ability for the servers to be working properly and not waste data-is a critical interest for many data centers. This reliability depends on many factors such as the characteristics of the servers used and the data center "infrastructure" which contains the power delivery system and cooling resources. Servers and other computing devices need continuous power supply system and are less susceptible to hardware breakdown when operating below a certain temperature. It is significant to mention that the servers can produce large amount of heatand, as a result, data centers often have large cooling loads [3]). Facility owners often use redundant computing setups, 

resources to protect server machines from failure.

The level of redundancy in the power generation system and cooling resources are usually used to evaluate the rank of reliability in data centers. This is known as the data center 'Tier level' [4] where higher Tier levels represent greater redundancy. Using redundant cooling resources, power delivery devices and UPS units increase the electrical energy consumed by the facilities. On the other hand, some buildings don't need such redundancies and equipment. As internet-based services have become increasingly used, datacenter establishment has increased. Through the period 2000 to 2010, the yearly establishment of data centers (in terms of money spent) increased over 300\%, from approximately $\$ 15$ billion USD to $\$ 50$ billion USD [5]. Some of this increased spending is linked to the more facilities being constructed annually, while others are linked to the increased redundancy in the newer facilities. That is, a 'Tier 4' data center can cost $\$ 22$ million USD/MW in comparison to $\$ 10$ million USD/MW for a 'Tier 1' facility [5].

The datacenter market can be split roughly into two sub-sectors: colocation and enterprise. Colocation, or "colo" operators provide what is known colloquially as "position, power and ping" which basically means that they provide the infrastructure - security, constant electricity supply, broadband connectivity and an environment in which temperature and humidity is controlled to suit servers. They then sell or lease space within those specialized facilities to companies who install and manage their own IT equipment. The term colocation comes from the fact that these customers share or "co-locate" their IT operations in one purpose built facility. Enterprise operators are those who use their datacenter provision for their own purposes - i.e. for their own corporate IT functions (in the case of banks and supermarkets and government departments). Enterprise operators also include those who provide IT services to third parties (HP, Fujitsu, IBM, BT, Atos, CapGemini, etc). Enterprise datacenter operators may build their own datacenter facilities or locate their datacenters within colo facilities - Many companies do both. Some companies operate enterprise datacenters but also sell some colo space to other companies, and this is a logical option for enterprise operators who find themselves with spare capacity.

As mentioned above, enterprise operators may build their own datacenters but for most it makes commercial sense to use a third party provider. Once an organization's data requirements reach a certain size or become mission critical (where disruption of service has significant adverse consequences and generates liabilities), this data will need to be housed in an environment with guaranteed levels of security, continuity of power supply and connectivity. Companies have a number of options here: They could build their own facility or they could take space from a wholesale or a colo operator and still manage their IT themselves or they could outsource the whole IT function to an IT services provider (who in turn may have their own datacenter or have taken space within a colo). They could even buy a site and then contract a third party to manage their IT for them within it. In this paper the authors focus on the situation that the company chooses to build its in-house and own datacenter from scratch.

The rest of the paper is organized as follows. Section 2 presents background about the proposed datacenter TCO models and spreadsheet tools, while the details about each model are discussed in section 3 .the comparison between the models is given in Section 4. Finally, section 5 concludes the paper.

\section{BACKGROUND}

In this part, the authors overview the proposed datacenter TCO models and spreadsheet tools . The calculations and estimations of TCO of the data centers don't have any recognized standards or 
rules; they depend on the size, location and design of datacenters [6]. .Many TCO models have been proposed for guiding datacenters design [7], [8], [9], [10], [11] that mainly depend on two types of datacenter costs the capital costs and operating costs for running the datacenter. Only few tools are publicly available to calculate TCO. APC [12] [13] provide an online estimator tools while [10], [14] provide spreadsheets to estimate the TCO. These tools can be used to assess the benefits and drawbacks of datacenter design choices on the TCO and the environmental impact but they do not allow easy exploration and fine grain design choices.

Based on these TCO models and tools, the authors divided Datacenter environment into number of IT equipment and number of operating devices required for operating the IT equipment. The authors collect the different devices and parameters in the datacenter and show them in Table [1].

Table 1. The Different devices in Datacenter.

\begin{tabular}{|c|c|}
\hline IT Equipment & Operating devices and systems for IT equipment \\
\hline Server machines & Power delivery and generation systems including (UPS \\
storage equipment & systems and power distribution units (PDU)) \\
Networking machines & Cooling resources \\
& Fire protection systems \\
& Raised floor / dropped ceiling (may be needed or not) \\
& enclosures and containment (Racks) \\
& Lighting system \\
\hline
\end{tabular}

The TCO models and spread sheet tools also helped the authors to know the different kinds of expenses in datacenters. The TCO of a datacenter includes Capital expenses and other Operational expenses. The authors in this survey designed diagram [1] to show the different costs in datacenters.

\section{Capital COSTS}

Hardware price

Hardware price of IT devices

Hardware price of Operating devices and systems for IT equipment

basic installation, Design /engineering costs

basic installation, Design /engineering costs for IT devices

basic installation, Design /engineering costs for Operating devices and systems for IT equipment

project management / facility engineering cost

\section{OPERATION COST}

Power consumption cost

The cost of electricity for IT equipment ( servers, networking equipment and storage system.)

the cost of electricity for cooling resources

the cost of electricity for power delivery and generation system

the cost of electricity for lightning system

Personnel cost (personnel salaries)

Maintenance and repairs costs

(depreciation) costs

depreciation cost of IT equipment

Depreciation cost of all other Operating devices and systems for IT equipment including (power delivery and cooling systems, racks ...).

IT software license cost 


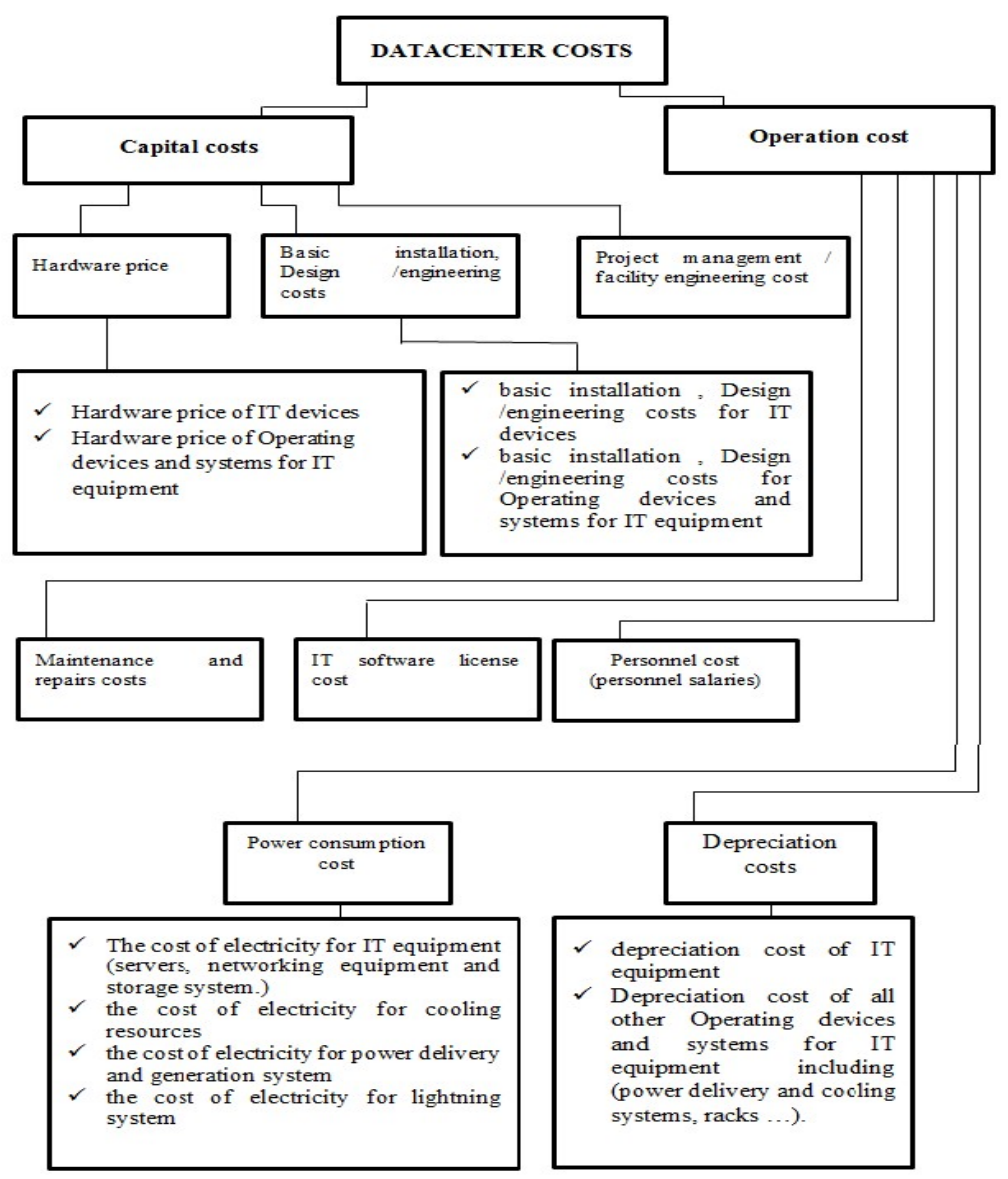

Diagram [1] different costs in datacenter

Another important cost component must be included in datacenter TCO model is space cost. as it is mentioned before, some companies tend to build their datacenter building from scratch or rent space to house their datacenter devices or choose to buy already constructed building and use it for their own needs and purposes .If the companies choose to build their own datacenter building from scratch ,then cost of land and Construction costs of a datacenter building must be included and they are considered as capital costs and in that case, the established datacenter building will have a deprecation cost (operation cost) and land doesn't have deprecation cost but if the companies choose to rent space, cost of renting space should be included in Datacenter TCO model and, it is considered as operating cost because it is continually paid during datacenter life cycle Or if the companies choose to buy already constructed building, the price of building should be included in TCO model and it is considered capital cost and it also will have deprecation cost (operation cost). The authors in this survey designed the following diagram [2] to show the different options that the customer can choose between from when planning for establishing datacenter. 
International Journal of Computer Science, Engineering and Applications (IJCSEA) Vol. 8, No. 2/3/4, August 2018

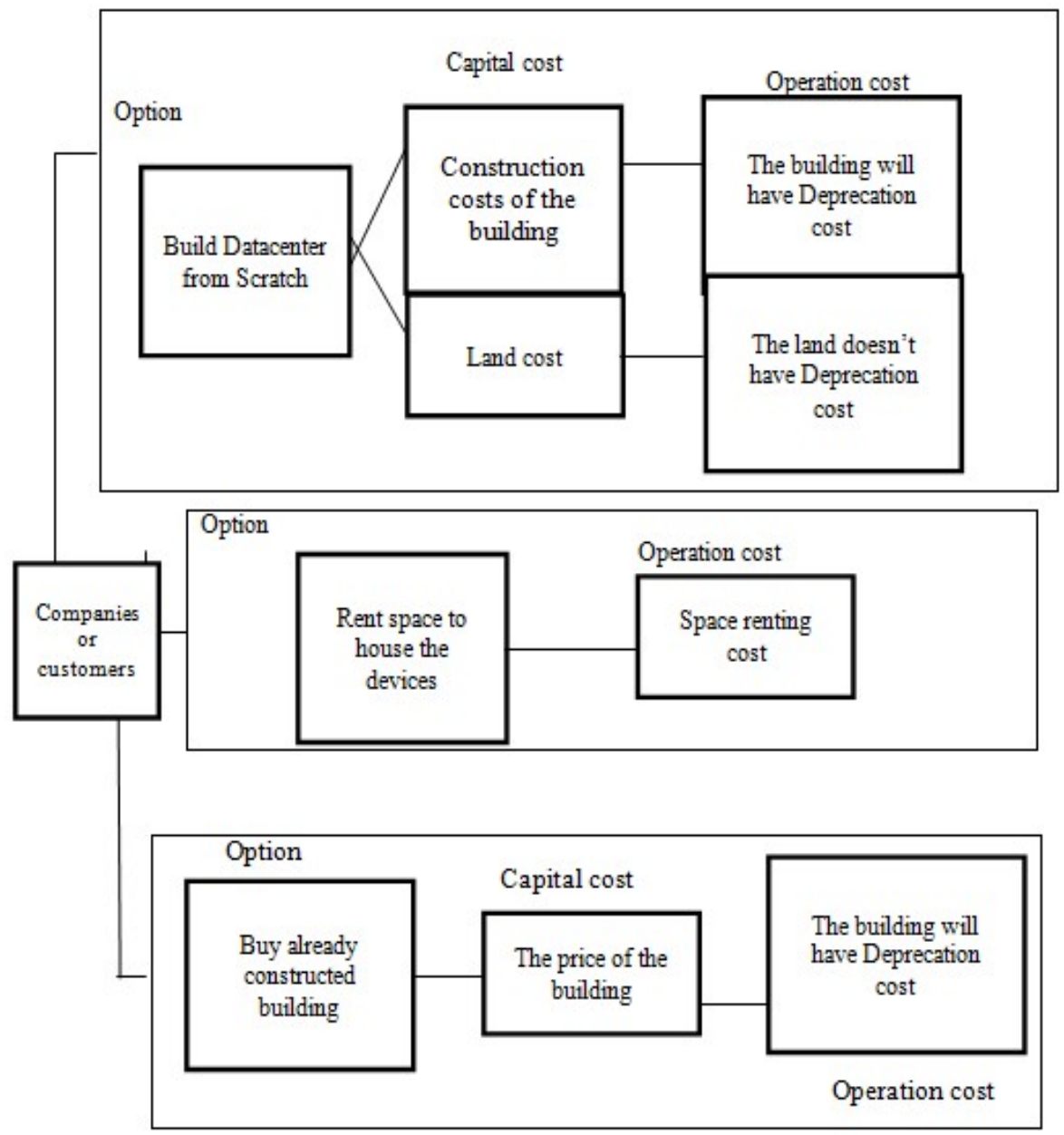

Diagram [2] different options for the customers

In this survey, the authors compare between Numbers of models and publicly available tools which are used to calculate TCO. The comparison is done to guide the users of tools about the parameters that aren't included in the tools and must be taken in consideration when calculating the total datacenter cost and show if the tool is documented or not.

\section{Datacenter Tco Models And Spread Sheet Tools 3.1 Cost Model For Planning, Development And Operation Of A Data CENTER}

The cost model proposed by HP Laboratories take into account all costs which are involved in operating the data center of an organization: cost of power delivery, cost of cooling, cost of space and cost of operation. The total cost of ownership of a datacenter is summarized in equation [1] as follows:

Cost total $=$ Cost space + Cost power the hardware + Cost cooling + Cost operation [1]

Each of these costs expresses the "amount" of correspondent resource, consumed by the data center in a specific period of time. The methods for calculating them are detailed in [7]: 
International Journal of Computer Science, Engineering and Applications (IJCSEA) Vol. 8, No. 2/3/4, August 2018

Typically, the cost of space includes the cost of real estate necessary for the data center, for power generation systems and other auxiliary subsystems. It is considered that operating income is realized only in that portion of the data center space which is populated with computing equipment;

Cost of power delivery includes conditioning, battery back-up, on-site power generation, and redundancy in both delivery as well as generation;

Cost of cooling is the cost of power consumed by the cooling resources;

Cost of operation includes personnel costs, depreciation of IT Equipment, software and licensing costs.

This model offers a method for calculating the total costs of a data center but the authors of this study do not go any further in finding any costs related to the Fire protection systems, enclosures and containment (Racks) and Lighting system. Another significant note observed in this model is that The cost of electricity for IT equipment and the cost of electricity for cooling resources are included in the cost model but the cost of electricity for power delivery and generation system And the cost of electricity for lightning system are not taken in consideration by the authors in the model. Basic installation, Design /engineering costs and project management / facility engineering costs are also not included in the cost model.

The authors of this study discussed their calculations about datacenter TCO in [7] but they didn't present spread sheet tool.

\subsection{Over All Datacenter Costs}

The author of this study provided a spreadsheet tool to estimate the datacenter TCO. The tool is publicly available for download at [15]. Many researches said that power is the dominate cost in a large-scale data center". Servers dominate with mechanical systems and power distribution close behind but the author showed in this model that power is incredibly important but it's not the utility $\mathrm{kWh}$ charge that makes power important, it's the cost of the power distribution equipment required to consume power and the cost of the mechanical systems that take the heat away once the power is consumed (cooling infrastructure). The author referred to this as fully burdened power. Measured this way, power alone itself isn't anywhere close to the most significant cost and it is the second most important cost.

The main challenge is how to compare between the capital costs of datacenter devices with that monthly bill for power? To know the dominate cost in datacenter. The amortization periods are completely different. Data center amortization periods run from 10 to 15 years while server amortizations are typically in the three year range. Servers are purchased 3 to 5 times during the life of a datacenter.

The author in this model solved that challenge by normalizing all costs to a monthly bill by taking consumable like power and billing them monthly by consumption and taking capital expenses like servers, networking or datacenter infrastructure (power distribution and cooling), and amortizing over their useful lifetime using a $5 \%$ cost of money and, again, billing monthly. This approach helps in comparing non-comparable costs such as data center infrastructure with servers and networking gear each with different lifetimes. 
The users can enter the inputs about their datacenter environment in the spread sheet tool and based on these inputs the tool automatically calculate the monthly depreciation costs and the monthly power consumption cost.

The tool includes all costs "below the operating system" but the software licensing costs are not included because the author thought that open source is dominant in high scale datacenters and licensing costs can vary so widely. Administrative costs are not included for the same reason. Hardware administration, security, and other infrastructure-related people costs disappear into the single digits with the very best services down in the $3 \%$ range. Because administrative costs vary so greatly, the author didn't include them in the model.

In the spreadsheet tool, the facility server count is kept to be big enough in the 45,000 to 50,000 server range. The author only modeled those techniques well understood and reasonably broadly accepted as good quality data center design practices, but Most of the big operators will be operating at efficiency levels far beyond those used in this tool. For example, in the tool the author is using a Power Usage Efficiency (PUE) of 1.45 but Google, for example, reports PUE across the fleet of less than (1.2). The PUE value in the tool can be changed by the users as appropriate.

The model isn't documented but the spread sheet is available at [15] and the article about the tool can be read at [14].

\subsection{A Simple Model for Determining True Total Cost Of OWnership For DATA CENTERS}

The author introduced spreadsheet tool for calculating the true total cost of ownership (True TCO) that can help in defining all the components of data center costs, including both operating and capital costs (OpEx /CapEx). The spreadsheet tool can be downloaded at [16] .Companies can use the spreadsheet tool and the inputs can be edited to reflect any company's particular circumstances.

In this study, the TCO model was split into IT hardware and software such as servers, disks, tape storage, and networking. This model had taken the energy usage and cost into consideration. In turn, this model developed a relation to current technology data for other high-performance computing program's financials. Furthermore, this TCO model recommended that data center's evaluate their "architectural and engineering fees, land, inert gas fire suppression costs, IT buildout costs for racks, cabling, internal routers and switches, electricity costs, security costs, and operations and maintenance costs for both IT and facilities." This allowed the data center to better assess their energy usage as well as their IT expenditure .a detailed layout of the spreadsheet used to hold this relevant information is in [10].

The authors of this model collected the model assumptions and calculations in table. They split the IT hardware into servers, disk storage, tape storage, and networking categories. They estimated the power used by IT hardware (IT loads). electricity consumed by cooling devices and electricity consumed by Auxiliaries systems were estimated and added to IT load to get the Total electricity use of datacenter. They calculated the total annual power cost. Cooling devices include (fans, chillers, CRAC units and pumps) and Auxiliaries systems include ((lights, UPS/PDU losses, and other losses).the total electricity of the datacenter is shown in equation [2].

Total electricity of the datacenter $=$ IT loads + cooling loads + Auxiliaries systems load [2] 
International Journal of Computer Science, Engineering and Applications (IJCSEA) Vol. 8, No. 2/3/4, August 2018

The authors of this study calculated the Total electricity costs and added them to network fees and other operating expenses per year to get Total annual datacenter operating expenses. Other operating expenses include IT site management staff, Facilities site management staff, Maintenance, Janitorial and landscaping and Security costs. Total annual datacenter operating expenses

Total annual datacenter operating expenses $=$ Total electricity costs + network fees + other operating expenses [3]

The authors also take in consideration the capital costs of all devices mentioned in table [1] including IT equipment, the site infrastructure (cooling and auxiliary devices). The model also calculates Rack costs, Land costs, Architectural and engineering fees, Interest during construction, Inert gas fire suppression and other facility costs.

The model doesn't include application software and Operating system licenses costs which are an important factor that must be included to get overall cost required for datacenter running.

\subsection{Datacenter Capital Cost Calculator Tool}

Datacenter capital cost calculator [12] is a new Web-based application presented by Schneider Electric with easy-to-use interfaces designed for use in the early stages of datacenter concept and design development.

The aim of launching that tool is defining the datacenter physical infrastructure parameters and calculating estimated costs based on the various parameters inputs. The tool provides calculations about the required number of racks, the required floor space, and the whole capital cost based on the user's inputs of the key power and cooling infrastructure, level of redundancy, and the IT load identification. This tool presents rough order of magnitude values. The results of this calculator help users to know how changes in IT load, location of datacenter, cooling and power infrastructure can affect the whole capital costs.

The data center capital cost calculator can be an invaluable tool to help ensure that a particular design will be in line with the user project's budget, whether it be a new data center or a retrofit. Used early in the planning stages, it can quickly set users expectations as to what their data center project might cost. It'll give users a rough order of magnitude cost, $+/-20 \%$ (it's not meant to be a quoting tool), to help companies or users understand what different choices cost; and the tool can help to avoid the time and cost of cycling through iterations of change.

The tool is great for walking through different design scenarios to make decisions about competing design requirements. For instance, higher redundancy (i.e. tier 3 or 4) is something often known as a top priority, but budget has a direct impact on just how much redundancy is feasible. This tool helps companies see the numbers so they can make the appropriate decisions regarding capacity, criticality, density, budget, and more. There's not one particular business requirement that trumps the others. It really depends on the business needs.

\subsection{BaCkground On The Methodology Of The ToOL}

As mentioned in [17], the designers of the calculator tool first researched more about what the various data center subsystems cost. They obtained costs from actual configurations of their own systems, quotes from 3rd party suppliers, and also partners. 
International Journal of Computer Science, Engineering and Applications (IJCSEA) Vol. 8, No. 2/3/4, August 2018

Since they wanted a calculator that could compute the cost estimates for a wide range of data center styles \& sizes, they relied on data trending. All of their subsystem costs are in dollars per watt, dollars per sqft, or dollars per rack; and then baseline costs are adjusted with various multipliers:

Capacity multiplier - they collected cost data for two or more capacities for each subsystem, and then trend-lined the data to estimate any size system.

Density multiplier - they did the same thing for densities. For each subsystem, they determined the cost at $1 \mathrm{~kW} /$ rack vs. $15 \mathrm{~kW} /$ rack, and then we trend-lined the densities in-between.

Redundancy multiplier - Redundancy impacts material cost, design cost, and installation costs differently. Multipliers were established based on system costs and 3rd party design engineering and installation quotes.

Some key assumptions and data sources in the tool are:

Data center size - White space size is computed using $27 \mathrm{sqft} /$ rack. This is used to estimate certain costs like raised floor cost and lighting cost, which are priced as $\$ / \mathrm{sq} \mathrm{ft}$.

Labor rates - Labor rate data comes from a US Dept of Labor, Bureau of Labor Statistics, January 2008 report

Currency, Currency conversions are based on data from Oanda [18].

Scalability of subsystems - the tool designer assume certain subsystems and costs are not scalable for the purpose of estimating costs: things like engineering design cost, or raised floor cost, security, lighting costs, etc.

Based on the user inputs for location, capacity, density, power \& cooling architecture, labor, and redundancy, the tool will show the estimated total data center cost, and also breakdown the costs by system (i.e. power, cooling), subsystem (i.e. UPS, generator, switchgear), and by type (i.e. material, installation, engineering, etc.). the user can make changes on the fly to see how the results are impacted.

The tool has many options that user can select between them, the level of redundancy of operational equipment increase the capital cost. Some companies have small capital money and other companies have more budget which can be paid for the datacenter design so the level of redundancy depend on the available budget.

Probably many datacenters may have the same number and type of equipment but they are located in different countries so the equipment prices are different which affect the capital cost. Each user has different requirements and plans about the Datacenter environment design. The following figure shows the tool interface and design 
International Journal of Computer Science, Engineering and Applications (IJCSEA) Vol. 8, No. 2/3/4, August 2018

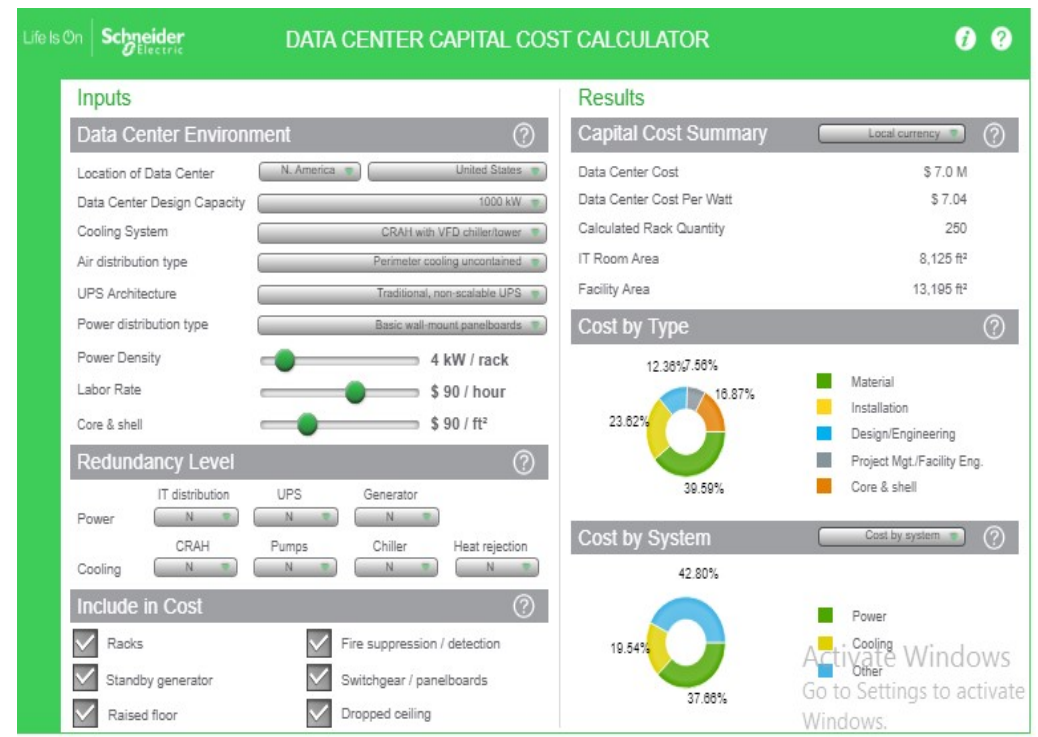

Figure 1 .the tool interface and design

\section{STEPS For USING The TOOL}

\section{To Use The ToOl, The User Should Follow The STEPS.}

Starting with selecting the continent. Then selecting country. Datacenter capital costs will be affected by the location due to the change in equipment costs and labor rates. Results are showed in the country's local concurrency, but can also be edited to other currencies.

Entering the datacenter IT load power consumption quantity in $\mathrm{KW}$, selecting a value between 40 and $5000 \mathrm{~kW}$.

Selecting a value for the Average power density in the datacenter between 1 and $20 \mathrm{~kW}$ per rack. Average power density has an influence on the space as well as number of required racks and

whole datacenter capital cost.

Choosing in the local concurrency the labor rate.

Selecting the cooling architecture, the user can select from one to thirteen cooling architecture. The architecture of cooling system in datacenter has a large impact on the capital costs. Perimeter cooling indicates that cooling devices are housed outside of the rows of racks, row based cooling presents cooling closer to the loads and includes ceiling-mounted and rack-mount cooling units. Air distribution is set to ducted hot air containment for the indirect air economizer architecture. Scalable static uninterruptible power supply systems allow scaling of capacity within a single UPS frame; this introduces increase in flexibility of redundancy and capacity.

Choosing from four power distribution Architectures within the IT space, overhead busway, remote power panels (RPPs), PDUs or wall mount panelboards.

Entering the value of the core and shell cost per square meter (or square foot), which involves the construction of the base building structure and envelope. The total core and shell cost will be calculated according to the facility total space, involving the IT, mechanical and electrical spaces. 
International Journal of Computer Science, Engineering and Applications (IJCSEA) Vol. 8, No. 2/3/4, August 2018

The total capital cost is calculated according to the user's inputs, selections in the level of redundancy for the power and cooling architecture impact the system design of other infrastructure system such as fire suppression /detection and security which means that the more redundancy (reliability) level selected for power and cooling architecture, the more reliability considered for the other systems. For example, selecting $2 \mathrm{~N}$ for cooling systems and $2 \mathrm{~N}$ for power systems would lead the fire suppression system to be VESDA with a clean agent for suppression.

The total capital cost can also involve other systems. Fire suppression /detection includes preaction sprinkler system using schedule $40 \mathrm{~m}$ black steel piping and detection using heat/smoke detectors with communication and alarm system.

According to the containment method, raised floor and/or dropped ceiling may be needed.

Datacenter cost introduces rough order of magnitude estimates of the datacenter, according to the user specifications of datacenter environment.

Input selections automatically drive the calculation of the number of the racks and the floor space required. The datacenter size refers only to the "IT room" and is used to compute raised floor and dropped ceiling costs.

Core and shell, lightening, fire protection and security are calculated based off of total datacenter size, including ancillary rooms housing physical infrastructure equipment.

The total datacenter system cost includes the materials, installation, designing /engineering, project management / facility engineering, and core \&shell.

This tool calculates the capital cost of the datacenter physical infrastructure but it doesn't take in consideration the software license cost and the operational cost such as power consumption cost and other operational costs.

\subsection{VirTuALIZATION ENERgY COST CALCUlATORTOOL}

Virtualization Energy Cost Calculator is an online tool that can be used by users to aid in their data center planning decisions. The tool can be accessed in [13]

The purpose of this tool is to illustrate the energy savings resulting from the virtualization of servers within a datacenter. The tool allows the users to input data regarding datacenter IT capacity, load, number of servers, energy cost, and other datacenter elements. Both the "as is" and "to be" environmental characteristics can be entered as inputs. The tool then compares both environments (pre and post virtualization) in terms of percentage of savings and also calculates the impact on the annual electrical bill. The power usage effectiveness (PUE) of both environments is compared as is the savings allocation and the space utilization.

Here's how it works. The total power consumed by servers and the average server power draw is estimated based on three inputs; total IT load, the percent of load that is servers, and the number of servers. Then, based on post-consolidation inputs including the percent of servers that can be virtualized and the consolidation ratio, the tool estimates the new server power consumption (after virtualization). The following figure shows the interface and the design of the Virtualization Energy Cost Calculator tool. 
International Journal of Computer Science, Engineering and Applications (IJCSEA) Vol. 8, No. 2/3/4, August 2018

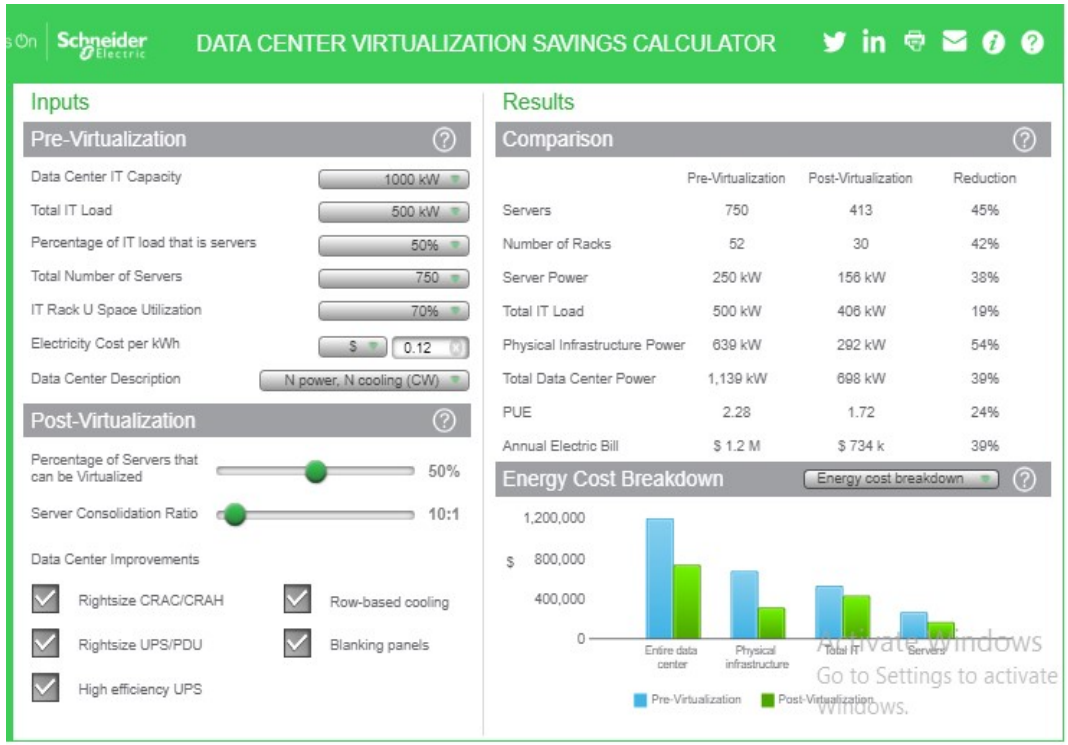

Figure 2 .the interface of the virtualization Energy Cost Calculator tool

Server consolidation is often where the energy discussion ends for virtualization projects, but this tool includes another critical aspect - the impact of the physical infrastructure on overall performance after a virtualization project. It is known that if the datacenter owners leave the power and cooling systems alone, and decrease their IT load through consolidation, the overall energy bill goes down (a good thing), but from the perspective of PUE or physical infrastructure efficiency, the data center just got worse. This tool helps the users see the impact of this, and allows them to see how power and cooling improvements like right-sizing the CRAC/CRAH or UPS, replacing outdated equipment with high efficiency systems, and improving airflow with targeted cooling and blanking panels can add significantly to the energy savings overall.

For the power \& cooling energy, this calculator allows the users to choose from six typical data center power $\&$ cooling architectures. These architectures vary in redundancy (i.e. $\mathrm{N}$ or $2 \mathrm{~N}$ ), and cooling approach (i.e. DX or chilled water). The users would pick the one that most closely aligns to their environment and then do some "what-ifs" with changes to their power \& cooling to see how the energy losses are impacted.

The space analysis within the tool is pretty straight-forward. It is assumed that each rack is $42 \mathrm{U}$ tall and requires 27 sq. $\mathrm{ft}$ ( 2.5 sq.m). Pre-virtualization servers are assumed to be $2 \mathrm{U}$ in height, while post-virtualization servers are assumed to be $2 \mathrm{U}$ for consolidation ratios less than 4 and $3 \mathrm{U}$ for consolidation ratios greater than 4 .

More details about the topic of virtualization and how optimized power \& cooling can maximize the energy benefits are illustrated in [19]. This research also discussed the power and cooling challenges associated with virtualization, how to improve the PUE, impact of virtualization on redundancy requirements, and how dynamic loads can impact the risk of downtime if rack-level power and cooling health are not considered.

To use the spreadsheet tool, the user should follow the steps:

Entering the datacenter IT capacity

The datacenter IT capacity is the maximum amount of power the datacenter can provide to the critical IT load. 
Entering the IT load

The IT load is the amount of power consumed by servers, storage and networking machines.

Entering the percentage of IT load that is servers

The percentage of IT load that is servers refers to \% of the total IT load consumed by servers. Typical datacenters are in the $50-60 \%$ range.

Entering The total number of servers

The total number of servers is the amount of actual physical servers (not virtual servers).

Entering The IT rack U space utilization

IT rack $U$ space utilization is the average \% of vertical height consumed by the IT (assuming 42U racks).

Entering the Electricity cost per KWh

The users should first choose the currency type and then enter the value of the cost. The electricity rate represents an average that takes into account peak and off-peak rates.

Choosing the datacenter description

The datacenter choices all include generator, raised floor, hot/cold aisle, perimeter coolers. $\mathrm{N}$ power, $\mathrm{N}$ cooling $(\mathrm{CW})$ : 1N UPS, PDU, Chiller, cooling tower, pumps \&CRACHS.

$\mathrm{N}$ power, $\mathrm{N}$ cooling $(\mathrm{DX})$ : same as previous except cooling is air-cooled $\mathrm{DX}$ $2 \mathrm{~N}$ power, $\mathrm{N}$ cooling $(\mathrm{CW})$ : same as first except $2 \mathrm{~N}$ UPS, PDU with STS.

$2 \mathrm{~N}$ power, $\mathrm{N}$ cooling (VFD CW): same as previous except pumps and Chillers include VFD

$2 \mathrm{~N}$ power, $2 \mathrm{~N}$ cooling $(\mathrm{CW})$ : same as previous except cooling systems are $2 \mathrm{~N} \&$ don't use VFD. $2 \mathrm{~N}$ power, $\mathrm{N}$ cooling (VFD CW): same as previous except all pumps \& Chillers include VFD

All these inputs are about the pre virtualization datacenter environment

Other inputs should be entered by users as follows

Entering the value of percentage of servers that can be virtualized

More and more IT applications are becoming candidates for virtualization, the percentage of servers that can be virtualized depends on various business requirements and the specific applications.

Entering the server consolidation ratio

A typical value for server consolidation is $10: 1$, but can vary substantially, based on server specifications and business applications.

The users of the tool also have the option to select number of choices for improving datacenter environment such as the choice of Installation of blanking panels and the choice of a row -based cooling. Here are the benefits of each choice

Oversizing is the traditional practice of purchasing excess capacity up front to accommodate potential long term growth, right sizing implies scalable solutions that can grow or decrease capacity only when required with minimal upfront investment.

Modern UPS attain higher efficiencies than their traditional counterparts. A change in efficiency of just a few percentage points can significantly reduce energy consumption

A row -based cooling approach brings the source of the cool air closer to the IT load this gain in cool air distribution efficiency helps reduce energy bills.

Installation of blanking panels to eliminate gaps and spaces in racks helps to manage the efficient removal of hot air from the IT loads thereby increasing the efficiency of the cooling system.

Based on user inputs, the tool automatically calculate number of servers and racks, Power consumption of IT equipment and the physical infrastructure, and the annual electrical bill. 
The tool only calculates the annual power consumption cost of datacenter before and after using virtualization technology. All other costs such as maintenance cost or software license cost are not calculated in that too

\section{The Comparison Between Datacenter Tco Models And Spread SHEET TOOLS}

In this section, the authors of this survey compare between datacenter TCO models and spread sheet tools. The authors use the different cost parameters mentioned in diagram [1] to compare between the datacenter TCO models and spread sheet tools. The comparison is based on many aspects such as what are the parameters included and not included in such tools and whether the tools are documented or not. The following table shows the comparison

Table 2 .the comparison between the datacenter TCO models

\begin{tabular}{|c|c|c|c|}
\hline Cost model & $\begin{array}{l}\text { Parameters included in } \\
\text { the cost model }\end{array}$ & $\begin{array}{l}\text { Parameters not } \\
\text { included in the cost } \\
\text { model }\end{array}$ & $\begin{array}{l}\text { The model } \\
\text { documented } \\
\text { or not }\end{array}$ \\
\hline $\begin{array}{l}\text { Cost model for } \\
\text { planning, } \\
\text { development } \\
\text { and operation of } \\
\text { a data center }\end{array}$ & $\begin{array}{l}\text { Datacenter operating costs } \\
\text { Space cost } \\
\text { Power consumption cost } \\
\text { The cost of electricity for IT } \\
\text { equipment } \\
\text { the cost of electricity for } \\
\text { cooling resources } \\
\text { Software and Licensing Costs } \\
\text { Personnel Costs } \\
\text { Depreciation costs }\end{array}$ & $\begin{array}{l}\text { All costs related to the } \\
\text { following systems are } \\
\text { not included } \\
\text { the Fire protection } \\
\text { system } \\
\text { enclosures } \\
\text { containment (Racks) } \\
\text { Lighting system } \\
\text { The following capital } \\
\text { costs also are not } \\
\text { included installation, } \\
\text { Basic /engineering } \\
\text { Design } \\
\text { costs } \\
\text { project management } \\
\text { facility engineering costs } \\
\text { operation cost : power } \\
\text { consumption cost } \\
\text { the cost of electricity for } \\
\text { power delivery } \\
\text { generation system } \\
\text { the cost of electricity for } \\
\text { lightning system }\end{array}$ & $\begin{array}{l}\text { The model is } \\
\text { documented and } \\
\text { available at [1] }\end{array}$ \\
\hline $\begin{array}{l}\text { A simple model } \\
\text { for determining } \\
\text { true total cost of } \\
\text { ownership for } \\
\text { data center }\end{array}$ & $\begin{array}{l}\text { All Capital cost } \\
\text { Hardware price } \\
\text { land cost } \\
\text { building cost } \\
\text { basic installation , Design } \\
\text { /engineering costs } \\
\text { project management / facility } \\
\text { engineering cost } \\
\text { Operation cost } \\
\text { Power consumption cost } \\
\text { Personnel cost (personnel } \\
\text { salaries) } \\
\text { Maintenance and repairs } \\
\text { costs(depreciation) costs }\end{array}$ & $\begin{array}{l}\text { Operating system } \\
\text { licenses and application } \\
\text { software }\end{array}$ & $\begin{array}{l}\text { The model is } \\
\text { Documented } \\
\text { and available at } \\
{[10]} \\
\text { The spread } \\
\text { sheet is } \\
\text { available at [16] }\end{array}$ \\
\hline
\end{tabular}


International Journal of Computer Science, Engineering and Applications (IJCSEA) Vol. 8, No. 2/3/4, August 2018

\begin{tabular}{|c|c|c|c|}
\hline $\begin{array}{l}\text { Overall data } \\
\text { center } \quad \text { costs } \\
\text { model }\end{array}$ & $\begin{array}{l}\text { Operation cost } \\
\text { Power consumption cost } \\
\text { The cost of electricity for IT } \\
\text { equipment } \\
\text { (depreciation) costs }\end{array}$ & $\begin{array}{l}\text { hardware administration, } \\
\text { security, and other } \\
\text { infrastructure-related } \\
\text { people costs (personnel } \\
\text { cost) } \\
\text { Power consumption cost } \\
\text { the cost of electricity for } \\
\text { cooling resources } \\
\text { the cost of electricity for } \\
\text { power delivery and } \\
\text { generation system for } \\
\text { the cost of electricity for } \\
\text { lightning system } \\
\text { Maintenance and repairs } \\
\text { costs license cost } \\
\text { IT software lice } \\
\text { basic installation } \\
\text { Design /engineering } \\
\text { costs paject management / } \\
\text { project } \\
\text { facility engineering cost }\end{array}$ & $\begin{array}{l}\text { The model isn't } \\
\text { documented but } \\
\text { the spread sheet } \\
\text { is available at } \\
{[15]} \\
\text { the article about } \\
\text { the spread sheet } \\
\text { is available at } \\
{[14]}\end{array}$ \\
\hline $\begin{array}{l}\text { Virtualization } \\
\text { Energy Cost } \\
\text { Calculator tool }\end{array}$ & Power consumption costs & $\begin{array}{l}\text { All capital costs and the } \\
\text { other operation costs are } \\
\text { not calculated in the tool }\end{array}$ & $\begin{array}{l}\text { The model isn't } \\
\text { documented but } \\
\text { the online } \\
\text { estimator tool is } \\
\text { available at [13] }\end{array}$ \\
\hline $\begin{array}{l}\text { APC [12] } \\
\text { Datacenter } \\
\text { capital cost } \\
\text { calculator }\end{array}$ & $\begin{array}{l}\text { Hardware price of Operating } \\
\text { devices and systems for IT } \\
\text { equipment } \\
\text { core and shell cost } \\
\text { basic installation , Design } \\
\text { /engineering costs for } \\
\text { Operating devices and systems } \\
\text { for IT equipment } \\
\text { project management / facility } \\
\text { engineering cost }\end{array}$ & $\begin{array}{l}\text { All other costs are not } \\
\text { included in that tool }\end{array}$ & $\begin{array}{l}\text { The model isn't } \\
\text { documented but } \\
\text { the online } \\
\text { estimator tool is } \\
\text { available at [12] }\end{array}$ \\
\hline
\end{tabular}

\section{CONClusion}

In this work, the authors have reviewed datacenters key concepts and attributes and provided a thorough background of the importance of datacenters in businesses. the authors have presented inclusive assessments and comparisons between several datacenter TCO spread sheets and tools. The comparison is based on the cost parameters included and not included in the cost model and if the model is documented or not. Such an approach provides a solid ground for designing better models in the future. 


\section{REFERENCES}

[1] J. G. Koomey, "Worldwide electricity used in data centers," Environmental research letters, vol. 3, p. 034008, 2008.

[2] W. P. Turner IV and K. G. Brill, "Cost model: Dollars per kW plus dollars per square foot of computer floor," Uptime Institute, 2008.

[3] T. ASHRAE, "Datacom equipment power trends and cooling applications," ed: American Society of Heating, Refrigerating and Air-Conditioning Engineers, Inc. Atlanta, 2005.

[4] N. CRAFT, "Explain: Tier 1 / Tier 2 / Tier 3 / Tier 4 Data Center", nixCraft Website, 29 January 2011," ed.

[5] C. Belady, "Projecting annual new datacenter construction market size," Microsoft, Global Foundation Services Report, 2011.

[6] N. Rasmussen, "Determining total cost of ownership for data center and network room infrastructure," Relatóriotécnico, Schneider Electric, Paris, vol. 8, 2011.

[7] C. D. Patel and A. J. Shah, "Cost model for planning, development and operation of a data center," ed, 2005.

[8] J. Karidis, J. E. Moreira, and J. Moreno, "True value: assessing and optimizing the cost of computing at the data center level," in Proceedings of the 6th ACM conference on Computing frontiers, 2009, pp. 185-192.

[9] J. D. Moore, J. S. Chase, P. Ranganathan, and R. K. Sharma, "Making Scheduling" Cool": Temperature-Aware Workload Placement in Data Centers," in USENIX annual technical conference, General Track, 2005, pp. 61-75.

[10] J. Koomey, K. Brill, P. Turner, J. Stanley, and B. Taylor, "A simple model for determining true total cost of ownership for data centers," Uptime Institute White Paper, Version, vol. 2, p. 2007, 2007.

[11] K. V. Vishwanath, A. Greenberg, and D. A. Reed, "Modular data centers: how to design them?," in Proceedings of the 1st ACM workshop on Large-Scale system and application performance, 2009, pp. 3-10.

[12] Datacenter capital cost calculator https://www.schneiderelectric.com/en/work/solutions/system/s1/data-center-and-network-systems/trade-off-tools/datacenter-capital-cost-calculator/tool.html.

[13] Virtualization Corgy Calculator https:/www.schneiderelectric.com/en/work/solutions/system/s1/data-center-and-network-systems/trade-off-tools/datacenter-virtualization-energy-savings-calculator/tool.html

[14] J. Hamilton, "Overall data center costs," Perspectives at http://perspectives.mvdirona.com/2010/09/18/ overalldatacentercosts.aspx. mvdirona. com, 2010.

[15] Overall data center costs http://mvdirona.com/jrh/TalksAndPapers/PerspectivesDataCenterCostAndPower.xls

[16] A simple model for determining true total cost of ownership for data centers https://virtualizationandstorage.files.wordpress.com/2014/05/truetco_model_2-1.xls

[17] W.Torell, "Data Center Capital Cost Calculator - A Tool to Help Älign Your Data Center Business Requirements with Your Project Budget" https://blog.schneiderelectric.com/datacenter/2012/06/28/data-center-capital-cost-calculator-a-tool-to-help-align-your-datacenter-business-requirements-with-your-project-budget/

[18] Oanda https://www.oanda.com/currency/converter/

[19] P. Niles and P. Donovan, "Virtualization and Cloud Computing: Optimized Power, Cooling, and Management Maximizes Benefits. White paper 118. Revision 5," Schneider Electric, Tech. Rep2015. 